\title{
The Importance of PRI Therapy for the Pastoral Counsellor
}

\author{
Anke Bisschops
}

Published online: 2 July 2009

(C) The Author(s) 2009. This article is published with open access at Springerlink.com

\begin{abstract}
It is not always easy for pastoral counsellors to help people change. Often people have become stuck in their ways. Recent developments in the field of brain research help explain why change is difficult. This article discusses Past Reality Integration Therapy (PRI), a psychotherapeutic method that integrates recent findings of brain research and offers an important addition to the work of (pastoral) counsellors and psychotherapists. The use of this approach with Dutch students in their pastoral training is presented. Furthermore the importance of this new method for counsellors themselves, their clients and their work is discussed and some overall conclusions about the method and its practical application are presented.
\end{abstract}

Keywords Counselling $\cdot$ Psychotherapy $\cdot$ Change $\cdot$ Pastoral training

\section{Introduction}

We all are familiar with situations in which we suddenly feel overwhelmed by negative feelings, which are out of proportion. One moment we feel secure, "on top of things," competent, and the next moment we feel depressed, angry, insecure, guilty, ashamed, etc. For example: we are in a meeting and suddenly we feel the urge to make a special effort to please someone. Or we made a "to do" list and with every intention of completing the tasks we suddenly find ourselves watching TV, drinking a glass of wine, or looking for things to snack on in the refrigerator. These are all examples of situations in which we go from behaving and thinking as a reasonable and responsible adult to behaving and thinking like a child.

When people ask for the help of a pastoral counsellor, they often present similar kinds of problems. For instance, a person is afraid of conflicts and does not dare to confront a dominant colleague. Or a member of the congregation would like to use his time in a more

\footnotetext{
A. Bisschops $(\bowtie)$

Tilburg University, Faculty of Catholic Theology, Heidelberglaan 2, 3584 CS Utrecht, The Netherlands

e-mail: a.m.h.bisschops@uvt.nl

e-mail: anke.bisschops@gmail.com
} 
efficient way, but cannot manage to do so. Someone else notices that she is unnecessarily insecure and stressed about the quality of her work (see also Bisschops 2005 and 2007a).

Often it is difficult to help people change and to encourage them to do things differently. Old patterns of behaviour strongly influence their reactions and they have become stuck in their ways of thinking, acting and feeling.

Recent scientific developments in the field of brain research increasingly help explain why change is so difficult. And, more importantly, these insights also reveal how changes in unwanted patterns of behaviour can be brought about. In the next paragraph I will discuss a new psychotherapeutical approach that integrates these developments.

\section{How to change old habits with past reality integration (PRI) therapy}

The Dutch psychologist Ingeborg Bosch recently developed a psychotherapeutical method, one that integrates the latest insights revealed by modern brain research. This method is called Past Reality Integration (PRI) and is currently on the rise, not only in the Netherlands, but also in France, Canada and Italy (Bosch 2003, 2005, 2002/7). Bosch's view on human growth towards adulthood offers a clear and practical conceptual framework to look at ourselves and to better understand what is happening with us in certain complicated situations (see also www.pastrealityintegration.com).

Modern brain research shows that the human organism is managed by two different types of brain: the rational brain (neo-cortex) and the much older emotional brain (limbic system) in which all emotional experiences, that were once experienced as dangerous, are stored, more specifically: in the amygdala (LeDoux 1996). This amygdala constantly scans our environment for signs of danger and it sounds the alarm as soon as it discovers similarities between dangerous situations from the past and the present situation. If it detects similarities, our nervous system is alerted and starts certain activities in order to help us "escape" from the situation we experience as dangerous.

However, situations that were once threatening for us as a child need not be threatening for an adult. Because the amygdala partly functions independently from our rational brain, it often does not help to tell ourselves that there is no real danger. Moreover, research shows that in certain situations the amygdala already has reacted before the neo-cortex, our rational brain, and even registers that there might be something wrong. In such situations we think we perceive the present, while in fact we are mostly experiencing the past. In extreme cases it is even possible that the rational brain is put "offline." So the amygdala regularly sounds a false alarm, for example in the case of panic attacks where there is no real danger at all, fooling the body into reacting as if it is actually experiencing a dangerous situation.

Although much is still to be discovered, it seems that PRI-therapy functions as a way of re-programming the amygdala, so that the major and minor, conscious and unconscious traumas of our childhood finally lose their grip on us, and old survival-mechanisms, which can have disastrous effects on our adult life, stop bothering us. It is assumed that new neurological pathways are formed in parts of our emotional brain, whereas changes in our rational brain (conscious behaviour and cognition) seem to happen as well (see also Dirken 2005).

So what are these survival-mechanisms?

Children are considered to be extremely flexible and capable of coping with many things, be it the death of a parent, emotional abuse or being excluded from a peer group. Bosch shows that this so-called resilience of children in fact is based on a very efficient system of 
repression and denial of the truth, which is supported by a wall of five different types of defences. These defences serve to enclose pain, which would be unbearable for the child to feel; they were indispensable for our psychological stability as a child. Just as our body has a physical defence or immune system, which encloses bacteria and viruses and renders them harmless, our psyche also possesses a defence or immune system that protects us from emotional harm. However, whereas our physical immune system is needed throughout our lives, as adults we no longer need this psychological defence-system, since adults are infinitely more capable of looking after themselves than children. In order to survive, as adults we do not depend exclusively on our parents anymore. We are capable of relativizing and of putting things in perspective, where children cannot. We can see that difficult situations are temporary, where children experience them as eternal. We are capable of fulfilling our basic needs ourselves. We have choices, etc. etc.

So as adults we not only can do without the old defence mechanisms that protected us as children, the defence mechanisms can even harm us as adults.

How does this work?

The five types of defences serve to protect the child from the devastating truth and the pain that it does not get what it needs for its physical and/or emotional survival. They do this by drawing all attention towards them. In fact the defences are illusions.

PRI therapy distinguishes five types of defences:

- Fear (if only such or so will not happen....)

- Primary Defence (I am bad, it is my fault, I am worthless etc.)

- False Hope (if I will do my very best, maybe things will be alright etc.).

- False Power (the other person is bad, it is their fault, they are wrong, not good, etc.)

- Denial of Needs (I do not need much, everything is alright with me, nothing is urgent).

Defences exist to protect us against experiencing life-threatening pain. This function of our defence mechanisms is easy to recognise in the example of the child whose parents are about to divorce. In general this is a very threatening and thus unbearable experience for a small child, so instead of feeling it the child escapes into one or more of its defences. For example, the child may develop a strong fear of being left alone (Fear), or feel guilty and blame itself for the divorce (Primary Defence); the child may develop pleasing behaviour, hoping his/her parents will stick together (False Hope) or the child may become aggressive or troublesome (False Power), and it may even withdraw and become absent-minded (Denial of Needs). Typically the different types of defences will alternate. It is important to note that for the child it is even less painful to be frightened, to feel inferior or guilty, to do its very best, to be angry or to feel nothing at all, than to feel the truth that its primary caregiver, on which it completely depends, both physically and emotionally, has disappeared from its life.

In our adult life, the old defence mechanisms come into view as soon as the amygdala detects similarities between a threatening situation from the past and a situation in the present reality. At that point the amygdala sounds the alarm. However it sounds the alarm unnecessarily, because although the child needed these defences to survive its childhood, for the adult these defences are the cause of much irrational behaviour and negative emotions, which are out of proportion. In the example of the child who lost a parent it may mean that as an adult $\mathrm{s} / \mathrm{he}$ develops what psychologists call separation anxiety. In fact it means that as adults we still defend ourselves from something that happened long ago and indeed felt terrible at that time, but that we can easily handle as adults. 
PRI-therapy: a threefold way to liberate oneself from the illusions that constitute our old coping mechanisms

Three aspects are central in this approach: thinking, acting and feeling. To start with, we need to learn to become aware of the moments that trigger our old pain and that cause us to react defensively: this is the cognitive (thinking) component of the therapy. Bosch calls situations in which our brain detects a similarity between a dangerous situation of the past and a present situation "Symbolic Situations." When we are triggered it is often difficult to see that there is nothing wrong, because the situation feels as if it is life threatening. That is the reason why this mechanism is much easier to recognise in others than in oneself. Secondly, in the behavioural component of the therapy it is important that we do not act upon the illusion that we need to protect ourselves against something which feels as life threatening. So we need to reverse the defences. This process relies on specific and concrete steps, which vary depending on the kind of defence that is active (Bosch 2003, p. 92). For instance, when we feel an extreme urge to get things done, as if our life depends on it, we need to stop this "False Hope" behaviour - the False Hope thought for example being: "If I try hard enough, 'it' will be alright." In general we are not aware that the "it" is something that happened in our past and that was life threatening for the child that we were. The third step in the PRI approach consists of feeling the "Old Pain." If we do not use the defence and instead reverse it, we can start feeling what the situation really does to us. This way we can get in touch with-regress to-the "Old Pain," from which the defensive reaction unnecessarily tried to protect us.

The aim of this three step process is to "re-program" the emotional brain (the amygdala), so that present events, which are not life threatening now, do not throw us off balance any longer and we can approach them as the adults that we are. In this way we will be able to liberate ourselves from persistent and destructive behavioural patterns. It is hard work and it takes a lot of dedication to learn how to not be controlled by our survival mechanisms. If we succeed in admitting the "Old Pain" and if we fully experience it, while simultaneously knowing who we are in the present and thus knowing that there is no danger-Bosch calls this "disidentified feeling"- the present situation looses its negative connotation and the emotional brain can be re-programmed. That way new neurological paths are formed (Dirken 2005).

The effects of PRI therapy are scientifically still under research but they are already quite convincing in clinical practice. It is interesting to note that PRI shows important similarities with another recently developed method of psychotherapy, which has indeed been proven to be effective: EMDR (Eye Movement Desensitization and Reprocessing) (Shapiro 2001; Servan-Schreiber 2003). Originally EMDR, which just as PRI has at its core the regression to the traumatic experience, was developed for the treatment of Post Traumatic Stress Disorders (PTSD), but it is also increasingly being used in the treatment of traumatic childhood experiences (De Jongh and ten Broeke 2004). An important difference between EMDR and PRI is that EMDR focuses on conscious and obviously severe traumas. PRI focuses mostly on less conscious and less obvious traumas. It starts at the other end with looking at disturbing and destructive defensive behaviour, through which childhood traumas can be accessed and uncovered.

\section{PRI in a training program for pastors}

In our educational program for pastors at the Faculty of Catholic Theology of the University of Tilburg, we pay attention to this approach at three different stages. The first 
stage is during a two-day residential seminar, which takes place in the year before students start their Master program. In this seminar the PRI theory is explained to the students and through working with so-called "Gestalts" they can experience how they themselves were changed by certain early childhood experiences. This also functions as an illustration of Bosch's insights.

The second stage at which we work with PRI is in the first year of the Master when students as a preparation for their practical year follow a "Communication and Leadership" course. In this course they learn about pastoral counselling, active listening, dealing with unacceptable behaviour of others, conflict handling, leadership, etc. During the last part of the course situations are discussed where although we know what to do ("active listening" for instance), we cannot manage to do so because perhaps unconsciously we have encountered "Old Pain." We examine what should be done about that: recognize that one is taken hostage by the emotional brain, try to stay out of the identification with the defence mechanism and possibly feel something of what it is in us that is triggered by this situation.

Finally PRI is again discussed in a workshop that takes place during the practical year. PRI knowledge is refreshed and the physical feeling component of PRI gets extra attention, so the students will distinguish more easily whether they are acting out of a defence or not.

Why so much attention for this theory in our educational program?

Firstly, the PRI approach offers an extremely clear and practical view on human growth and development. It can help the students in their own personal growth as well as better understand their clients.

As in all helping professions, pastoral workers themselves are their own main working instrument. Being a pastor, in particular a parish pastor, is a hard and demanding profession in present day secularised Netherlands. More than ever the social and emotional intelligence of pastors is crucial. During the training we try to develop these attitudes and skills among others with the help of PRI.

PRI is a self-help method, which demands a lot of self-reflection and introspection. As pastors because of their spiritual and religious attitude often are quite accustomed to paying attention to their inner world, PRI is particularly appropriate in this context.

What results do we see in our students by using PRI in our training program?

Feelings of shame about one's "shortcomings" are lessened when we are able to simply see them as defence mechanisms stemming from our childhood. Moreover it is reassuring when we realise we are not the only one and that everybody suffers from such feelings to a certain degree.

This effect is not to be underrated, because shame generally is a big obstacle for selfknowledge and personal growth. It is not easily shared with others and as a result people can needlessly remain stuck in destructive behaviours.

PRI insights also help in addressing people who are caught in a victim role. People who experience themselves as "victims" often only want confirmation or reassurance and they may perceive anything else as criticism. PRI insights can help to discuss the reality of their perception with such "victims," without them getting the feeling that we choose sides or let them down in some way or another.

PRI insights can help pastors to deal with reactions that are irrational or out of proportion from those entrusted to their care. Instead of becoming anxious and for example taking someone's anger personally, we can come to an understanding that the other person uses "False Power" as a defence and that apparently something painful from their past has 
been touched. So knowledge about the possible dynamics behind certain behaviour can lead to more helpful and compassionate reactions.

The effects of PRI teachings

The effects of PRI teachings should not be overestimated. The illusive defences can keep a firm grip on people. It is also important to note that although PRI can be applied independently, this is mostly only after one was well supported by a trained PRI therapist. There is a risk PRI is unknowingly applied out of False Hope ("if I do PRI well, than I will overcome all my troubles"). This False Hope can stimulate Primary Defence ("I can not do it; it is too difficult"), or it can end up in Denial of Needs ("there is nothing to worry about, it is an illusion anyway"). However when one's capacity of self-reflection and introspection (also called "the inner observer") is reasonably well developed and when one is motivated, it definitely works, especially when people are somewhat older and not so much caught up anymore in building up their life. They are then more capable to deal and get in touch with the feelings of "Old Pain." Often a lot is already gained if a person starts to realise and really understand that negative feelings about others (False Power) reveal more about oneself than about the other person.

\section{The importance of PRI for pastoral counsellors}

Knowledge about the insights of PRI is not only important for pastors-in-training, but also for those who counsel, supervise or otherwise support people. It is valuable in three ways: for their own personal process, for their clients and for the way in which they support, coach, and counsel their clients or parishioners.

The importance of PRI for counsellors themselves

The person who we are is at least as important for our professional effectiveness and personal impact as are our skills and knowledge. Counsellors also can be defensive every now and then; nobody is free of that. PRI offers an excellent, practical and manageable method of healing oneself. On the one hand it should not be too difficult for counsellors to learn to recognise when they are defensive. On the other hand, precisely because defences refer to our blind spots, professional support by a qualified PRI therapist is not a luxury even for counsellors. In any case it is important to re-program our amygdala and by doing so become more liberated. A (necessarily) short example to clarify this:

A counsellor recognises that he feels hurt whenever clients keep their distance during counselling sessions and they do not show much appreciation. Maybe the counsellor reacts by minimizing his feelings (Denial of Needs), by doing his very best (False Hope), by secretly blaming the client (False Power), by doubting his own capacities (Primary Defence) or by feeling apprehensive during his talks with this client (Fear). Being a professional, the first two reactions are most likely to happen, since they seem to be "reasonable" reactions. However if they originate out of defences, these reactions in fact serve to protect the counsellor against his own "Old Pain" and they are not as adequate as they seem to be.

Suppose this counsellor knows of PRI and recognises his defensive behaviour for what it is, for example "False Hope" (the cognitive component). Instead of trying even harder to 
gain his clients affection and appreciation, he stops that behaviour and reverses the defence (the behavioural component). In the case of "False Hope" reversing means that he formulates for himself what it is that he hopes to achieve with his "False Hope" behaviour. For example: "If I do my very best, this client will eventually start valuing me." Next he lets the "False Hope" collapse by imagining that he will never ever get what he is so desperately hoping for; whatever he does, the client will not appreciate him. If he then keeps concentrating on the feelings that come up in his body, he may get in touch with his "Old Pain." He may then start to feel how painful it was to be belittled by his distant father when he was a small boy.

As it is important to feel the pain as deeply as possible, he fully surrenders and gives in to the waves of sorrow, until they finally subside by themselves. In this way the experience can become integrated into the "Adult Consciousness" and the amygdala can be reprogrammed. The amygdala will become "convinced" as it were, that not being valued by someone is absolutely not life threatening (Bosch 2003, p. 108).

Henceforward in his dealings with aloof clients this counsellor will not be so much troubled by defences, which originate in his past. He will recognize them sooner for what they are and he will be able to reverse them, so that he can react to the present situation in the here and now out of his "Adult Consciousness."

The effects of this can hardly be overestimated. The less time and energy counsellors need to spend on defending themselves - unnecessarily and unconsciously-against something that is long past, the more time and energy they will have at their disposal to be there for their clients. Instead of being occupied with past and future, they become more present in the now. They can then perceive better, sense better, focus better and can become more spontaneous, creative and intuitive.

The importance of PRI for clients and parishioners

Our society becomes more and more demanding and increasingly poses challenges to our social, intellectual and emotional skills. PRI shows a way, which enables clients to improve their skills, either by entering PRI therapy first, or by applying PRI on their own in order to become aware of one's own defences and to learn to reverse them.

Furthermore if PRI concepts become shared knowledge in teams and organisations, they can serve to clarify situations and improve communication. To that end counsellors first need to have experienced what PRI is and what it can do, in order to be able to properly explain it to their clients.

One can object to this by stating that PRI is a therapeutic and not a pastoral or counselling approach. Such objections are partly based on the assumption that there are healthy and unhealthy people and that the treatment of unhealthy people is solely reserved for psychotherapists and psychiatrists. However everybody has suffered some damage in the course of their life. And counsellors cannot avoid addressing the issues of their clients every once in a while. Partly because PRI is quite easy to explain, it offers a good approach, except in those cases where there is too much damage and clients of course should be referred to a psychotherapist.

If only the cognitive component of PRI is raised during encounters with clients - and often that will be the case-PRI exhibits certain similarities with Rational Emotive Therapy (RET). However, because of its more elaborated conceptual framework, PRI seems more suitable to help people disidentify from their defences. (In RET-terms: to challenge ineffective thoughts). 
The importance of PRI for the way in which counsellors work with clients

The implications of PRI for the way counsellors work are countless. For one they learn to distinguish between three kinds of feelings. Firstly there are the feelings that come from our "Childhood Consciousness": Old Pain (lonely, lost, sad). Then there are the feelings that originate from our defences (anxious, guilty, stressed, angry, indifferent). And lastly we have authentic feelings that fit the situation and arise out of freedom; that is to say, they stem from our "Adult Consciousness" (mournful, sad, determined, compassionate, etc.). Each type of feeling needs a different approach. For instance the distinction between "Primary Defence" and "Old Pain" is essential, because although both are very painful, they need a completely different approach in terms of how to deal with them. The painful "Primary Defence" is an illusion that needs to be dismantled, whereas one should fully give in to "Old Pain" (see the example above).

One's own knowledge of and experience with PRI can help to recognise whether clients react to an old, unprocessed situation, or whether they react out of their "Adult Consciousness" to the situation here and now. The distinguishing factor is whether they react defensively or not. Some types of anger can be quite justified, for example when one does not want to be treated in a particular way. However, when that anger is out of proportion and the client her/himself feels as if it is — on a certain level—of vital interest to react this and no other way (which means that the client is completely taken over by the defence), then we can assume that there are two films running at the same time so to speak: one film of the present time and one of the past. Whether or not a client reacts from their defences determines the reaction as counsellor towards them. In cases of defences (the person is in fact reacting to something old) and if the counsellor considers it helpful to bring the client more in touch with his or her feelings, they may put the questions differently. Instead of asking: "How did you feel when he dominated you?" they might use a more general formulation: "How do you feel when someone dominates you?" The second way of putting it increases the possibility that the client will come closer to the original pain and it also decreases the pre-occupation with the present situation (and how "absolutely terrible" it is).

Sometimes clients appear to have great difficulty with certain events in their working environment. PRI enables people to take decisions and make choices based on actual facts in their present reality as an adult rather than on events that happened to them in their childhood. PRI can help to decide whether one does well in taking on the challenges of one's job or whether one does best in finding another job that does not trigger the "Old Pain" so much.

Another issue is the still growing popularity of the so-called "new spirituality." New spiritual leaders like Eckhart Tolle (1999, The Power of Now) and Byron Katie (2002, Loving What Is) call on people to be present in the here-and-now and to stop resisting what is. This call is heard by many, but at the same time it is felt to be extremely difficult to realise. The so-called "pain body," the collected pain from the past (Tolle) is usually the greatest obstacle here. PRI offers a practicable way to dismantle this big obstacle to being present in the here-and-now (Bisschops 2007b). With PRI insights counsellors will be able to connect especially well to clients that are spiritual seekers in this sense.

\section{Conclusion}

Above I discussed how difficult it is for us to change and to help others change. We saw how insights from recent brain research are helpful and how PRI therapy integrates these 
insights into a threefold approach of dealing with our defences. I showed how and why we pay attention to PRI in the training for pastors in our theological faculty in the Netherlands. Finally we considered the possible importance of PRI for counsellors themselves, for their clients and for the way in which counsellors work with their clients.

It is to be hoped that Bosch's views and insights eventually will become common knowledge in our society, for the sake of our children, for the sake of the mental health and well being of adults and for the sake of a better understanding between people. In order to achieve this, this relatively unknown approach needs more publicity. Pastoral counsellors can play an important role here. They however need to be informed about this interesting new development. This article contributes to this and hopefully will stimulate readers to further explore Bosch's work.

Open Access This article is distributed under the terms of the Creative Commons Attribution Noncommercial License which permits any noncommercial use, distribution, and reproduction in any medium, provided the original author(s) and source are credited.

\section{References}

Bisschops, A. (2005). De spoken uit het verleden bedwingen: Geborgenheid, compassie en afweermechanismen. Tijdschrift voor Geestelijk Leven, 5, 519-530.

Bisschops, A. (2007a). Tegenstrijdige behoeften en burnout: Een psychologische benadering. In A. Bisschops, et al. (Eds.), Verterend Vuur: Over burnout in het basispastoraat (pp. 165-177). Zoetermeer: Meinema.

Bisschops, A. (2007b). Globalisation and the new spirituality. Paper presented at the International Conference on Spirituality, Prague. https://praha.psu.cas.cz/spirituality/index.php?cmd=programme

Bosch, I. (2002/2007). Rediscovering the true self: A search for truth and healing. New insights combined with a comprehensive self-healing program. Holland: Ingeborg Bosch PRI b.v.

Bosch, I. (2003). Illusies: over bevrijding uit de doolhof van onze emoties. Amsterdam: Veen.

Bosch, I. (2005). Guérir les traces du passé: en quête de l'harmonie émotionnelle au présent. Montréal: Éditions de l'Homme.

De Jongh, A., \& ten Broeke, E. (2004). Handboek voor EMDR. Lisse: Swets \& Zeitlinger.

Dirken, G. (2005). Breincentraal leren. Leren in Organisaties, November, 9-16.

Katie, B. (2002). Loving what is: Four questions that can change your life. New York: Harmony Books.

LeDoux, J. E. (1996). The emotional brain: the mysterious underpinnings of emotional life. New York: Simon \& Schuster.

Servan-Schreiber, D. (2003). The instinct to heal: Curing anxiety, depression and stress without drugs and without talk therapy. New York: Holtzbrinck Publ.

Shapiro, F. (2001). EMDR: Eye movement desensitization and reprocessing: Basic principles, protocols and procedures. New York: Guilford.

Tolle, E. (1999). The power of now: a guide to spiritual enlightenment. Novato: New World Library. 